\title{
Clinical significance of interleukin-4 and interleukin-18 levels in aggressive non- Hodgkin's lymphoma patients
}

\author{
H.O. Soydinc ${ }^{1}$, N. Guney ${ }^{2}$, M. Basaran ${ }^{2}$, D. Duranyildiz ${ }^{1}$ and V. Yasasever $^{1}$ \\ ${ }^{1}$ Basic Oncology Department, Institute of Oncology, Istanbul University, \\ Istanbul, Turkey \\ ${ }^{2}$ Medical Oncology Department, Institute of Oncology, Istanbul University, \\ Istanbul, Turkey \\ Corresponding author: H.O. Soydinc \\ E-mail: hilaloguz@yahoo.com
}

Genet. Mol. Res. 15 (3): gmr.15038590

Received March 1, 2016

Accepted May 5, 2016

Published July 29, 2016

DOI http://dx.doi.org/10.4238/gmr.15038590

Copyright $(C 2016$ The Authors. This is an open-access article distributed under the terms of the Creative Commons Attribution ShareAlike (CC BY-SA) 4.0 License.

\begin{abstract}
Strong evidence indicates that tumor growth can be actively controlled by the immune system, and interleukins (ILs) are known to play an influential role in immune response regulation. Moreover, inflammatory cytokines are significantly involved in lymphoma pathogenesis. We aimed to investigate serum levels of IL-4 and IL-18 in aggressive non-Hodgkin's lymphoma (A-NHL) patients and their relationship with prognostic parameters and therapy outcome. These serum factors were measured by enzyme-linked immunosorbent assay in 46 patients with pathologically verified A-NHL before and after chemotherapy, and in 20 healthy controls. No significant difference in serum IL-4 $(\mathrm{P}=0.11)$ and IL-18 $(\mathrm{P}=0.261)$ levels was observed between the A-NHL and controls groups. None of the prognostic parameters analyzed significantly correlated with serum IL-4 concentration, while
\end{abstract}


only lactate dehydrogenase (LDH) measurements were associated with IL-18 values. Serum IL-18 was elevated in the patients with high LDH levels compared to those exhibiting normal values $(\mathrm{P}=0.045)$. In addition, no correlation was found between the concentrations of serum IL-4 and IL-18 in A-NHL patients $(\mathrm{r}=0.188, \mathrm{P}=0.187)$. While IL-18 values did not change, serum IL-4 levels decreased following chemotherapy, independently from treatment response $(\mathrm{P}=0.002)$. Our study is the first to report the response of serum IL-4 levels to chemotherapy. In conclusion, although IL-4 serum concentration has no diagnostic role, it is sensitivite to standard chemotherapy in A-NHL. However, serum IL-18 measurements have no diagnostic or prognostic role in this disease.

Key-words: IL-4; IL-18; Non-Hodgkin's lymphoma; Cytokines

\section{INTRODUCTION}

Although the etiology of non-Hodgkin's lymphoma (NHL) remains unclear, subclinical immune dysfunction is the most consistently identified risk factor, and dysregulation of cytokines may mediate its progression (Vendrame and Martínez-Maza, 2011). A variety of NHL subtypes are recognized, but cases are generally classified into two major groups: B- and T-cell lymphomas. Of the former, diffuse large B-cell lymphoma (DLBCL) and follicular lymphoma (FL) are the two most common subtypes. The exact causes of NHL remain largely unknown. However, immune dysregulation has been considered a hallmark of lymphoma (Zhang et al., 2015).

Aggressive NHLs (A-NHL) represent a heterogeneous group of malignancies that vary in biological pattern and outcome (Turner et al., 2010). The diagnosis and classification of NHL continue to be based on morphology and immunophenotype, and specific genetic changes are not taken into account in the definition of lymphoma subtypes. Certain recurrent molecular genetic abnormalities in NHL are associated with prognosis or represent potential therapeutic targets, thus there exists an emerging role for marker testing to help predict outcomes and guide therapy (Miles et al., 2016). Approximately half of A-NHL patients cannot be cured using standard treatment (Alici et al., 2003); therefore, the identification of new markers of treatment response and outcome is of some importance. Despite the description of a number of potential biomarkers, few have been integrated into clinical practice. The establishment of minimally invasive and easily accessible early diagnostic indicators is therefore necessary. Interleukins (ILs) play important roles in the pathogenesis of lymphomas and appear to be potential markers of tumor cell growth including that of NHL.

IL-4 is a cytokine produced by activated T lymphocytes (Paul, 1991). It exhibits pleiotropic activity, and can cause tumor regression via immunomodulation and/or direct antiproliferative effects. The effects of IL-4 include: stimulating growth of B and T lymphocytes (Spits et al., 1987); enhancing lymphokine-activated killer cell and cytotoxic T lymphocyte activity, especially when combined with IL-2 (Treisman et al., 1990); promoting growth of tumor-infiltrating lymphocytes (Kawakami et al., 1988); and stimulating differentiation and proliferation of hematopoietic cells (Saito et al., 1988).

Several reports have proposed a rationale for using IL-4 as therapy for patients with lymphoid malignancies (Parkinson et al., 1993). However, few prospective studies have

Genetics and Molecular Research 15 (3): gmr.15038590 
evaluated pre-diagnostic cytokine levels and subsequent NHL risk in immunocomponent populations (Purdue et al., 2011). IL-4 also modulates expression of human leukocyte antigen (HLA) class I and II proteins and cell adhesion molecules. These factors are relevant to lymphoma immunosurveillance and tumorigenicity, and are of particular clinical pertinence to large-cell lymphoma, in which the absence of HLA-DR expression is associated with poorer patient survival following chemotherapy (Miller et al., 1988).

IL-18, a member of the IL-1 family, is synthesized as an inactive precursor before being converted to a bioactive form because of cleavage by an IL- $1 \beta$-converting enzyme (Tas et al., 2015). IL-18 is a 18.3-kDa multifunctional cytokine synthesized by Kupffer cells, activated macrophages, keratinocytes, intestinal epithelial cells, osteoblasts, and adrenal cortex cells (Gillespie and Horwood, 1998). Human IL-18 stimulates cytotoxic natural killer (NK) cell activity and promotes the production of interferon- $\gamma$, IL-2, and granulocyte/ macrophage colony-stimulating factor by T cells (Ushio et al., 1996). Increased plasma IL-18 levels have been observed in acute lymphoblastic leukemia and chronic myelocytic leukemia patients (Taniguchi et al., 1997). Thus, IL-18 could be a useful and sensitive serum indicator of therapeutic effect and clinical course in haematologic malignancies (Taniguchi et al., 1997; Takubo et al., 2000a; Takubo et al., 2000b).

Knowledge of the serum levels of these cytokines in newly diagnosed A-NHL patients may help inform us of the possible prognosis and development of this disease, and decide on appropriate individualized therapeutic approaches.

This study was conducted to investigate IL-4 and IL-18 serum levels in A-NHL patients before and after chemotherapy and establish their relationship with prognostic parameters.

\section{MATERIAL AND METHODS}

\section{Patients}

Serum samples were obtained from 46 consecutively recruited A-NHL patients who had been referred to Istanbul University Institute of Oncology.

The clinical characteristics of these patients are summarized in Table 1. A number of clinical and pathological parameters were recorded, including age, tumor stage and histology, B-symptoms, extranodal lesions, performance status, bone marrow invasion, and serum lactate dehydrogenase (LDH) and $\beta 2$-microglobulin levels. Histopathological diagnosis was in accordance with the World Health Organization classification system (Turner et al., 2010).

The study population consisted of patients with newly diagnosed aggressive lymphoma, defined as DLBCL or grade III FL. As low-grade lymphomas are of lower priority in clinical and treatment terms, they were not included in the present study. Initial staging according to the Ann Arbor system was performed at diagnosis before initiation of treatment. Staging procedures included a computed tomography scan of the chest, abdomen and pelvis and unilateral bone marrow biopsy. Serum samples were obtained on admission and after completion of chemotherapy. All patients were treated with rituximab, cyclophosphamide, doxorubicin, vincristine, and prednisone at 3-week intervals. None of the patients had received previous therapy, including immunomodulators, cytokines or steroids.

Pregnant individuals, or those with severe infections, known allergic diseases, or poor performance status were excluded. Written informed consent was obtained from all participants before the investigation began and our study was approved by the Istanbul University Istanbul

Genetics and Molecular Research 15 (3): gmr.15038590 
Faculty of Medicine Ethical Committee (No.: 772). Control subjects $(\mathrm{N}=20)$ were recruited from among the Istanbul University Institute of Oncology personnel, and all were in excellent health at the time that the study was carried out.

\begin{tabular}{|c|c|c|c|}
\hline Parameter & & Value & $\%$ \\
\hline No. of patients & & 46 & 100 \\
\hline \multirow[t]{2}{*}{ Gender } & Male & 28 & 60.9 \\
\hline & Female & 18 & 39.1 \\
\hline Age (median,years) & & 52 & \\
\hline$\leq 60$ & & 34 & 74 \\
\hline$>60$ & & 12 & 26 \\
\hline \multirow[t]{2}{*}{ Histology } & Diffuse large B cell & 40 & 86.9 \\
\hline & \begin{tabular}{|l|} 
Follicular grade III \\
\end{tabular} & 6 & 13.1 \\
\hline \multirow[t]{4}{*}{ Stage } & I & 15 & 32.6 \\
\hline & II & 15 & 32.6 \\
\hline & III & 7 & 15.3 \\
\hline & IV & 9 & 19.5 \\
\hline \multirow[t]{2}{*}{ Response rate } & Complete & 39 & 84.7 \\
\hline & \begin{tabular}{|l|} 
Partial \\
\end{tabular} & 7 & 15.3 \\
\hline \multirow[t]{2}{*}{ B-symptoms } & A (Absent) & 27 & 58.6 \\
\hline & B (Present) & 19 & 41.4 \\
\hline \multirow[t]{3}{*}{ Performance status } & 0 & 24 & 52.2 \\
\hline & 1 & 14 & 30.4 \\
\hline & 2 & 8 & 17.4 \\
\hline \multirow[t]{2}{*}{ Bone marrow } & Positive & 2 & 4.3 \\
\hline & \begin{tabular}{|l|} 
Negative \\
\end{tabular} & 44 & 95.7 \\
\hline \multirow[t]{2}{*}{ Extra nodal lesion } & Yes & 17 & 37 \\
\hline & No & 29 & 63 \\
\hline \multirow[t]{2}{*}{ Serum LDH level } & $\leq 1 \mathrm{x}$ normal & 23 & 50 \\
\hline & $>1 \mathrm{x}$ normal & 23 & 50 \\
\hline \multirow[t]{3}{*}{ Serum $\beta 2$ - microglobulin } & $\leq 1 \times$ normal & 23 & 50 \\
\hline & $>1 \times$ normal & 16 & 34.88 \\
\hline & \begin{tabular}{|l|} 
Absent \\
\end{tabular} & 7 & 15.21 \\
\hline
\end{tabular}

$\mathrm{LDH}=$ lactate dehydrogenase

\section{Measurement of IL-4 and IL-18 levels}

Circulating IL-4 and IL-18 levels were evaluated by solid-phase enzyme-linked immunosorbent assay (ELISA; BioSource International, Inc., Camarillo, CA, USA) using 96well microplates following the manufacturer's protocol.

This assay comprises microtiter well strips coated with a monoclonal antibody specific for IL-4. Samples, including standards of known IL-4 content, control specimens, and unknowns, are then pipetted into the wells, followed by addition of a secondary biotinylated monoclonal antibody. During the first incubation, the IL-4 antigen binds to the immobilized (capture) antibody at one site and to the fluid- phase biotinylated antibody at a second site. After removal of excess secondary antibody, peroxidaseconjugated streptavidin is added. This binds to the biotinylated antibody to complete the four-member sandwich. After a second incubation and washing to completely remove unbound enzymes, a substrate solution is added, which is acted upon by the bound enzyme to produce color. Color development is arrested with Stop Solution and its intensity measured at $450 \mathrm{~nm}$ using an ELISA plate reader (ChroMate 4300; Awareness Technology

Genetics and Molecular Research 15 (3): gmr.15038590 
Inc., Palm City, FL, USA).

Similarly, for detection of IL-18, microtiter strips coated with a specific IL-18 monoclonal antibody were used. Samples, including standards of known IL-18 content, control specimens, and unknowns, were pipetted into these wells, and incubated for $1 \mathrm{~h}$. During this first incubation, IL-18 is captured and immobilized on the plate. After washing, a horseradish peroxidase (HRP)-conjugated anti-IL-18 antibody was added and the reaction incubated for $1 \mathrm{~h}$. The binding of this HRP conjugated antibody to the wells completes a three-member solid-phase sandwich. After a second wash step, HRP activity was detected by addition of 3,3',5,5'-Tetramethylbenzidine Substrate Reagent which produces color in proportion to the quantity of IL-18 contained in each sample.

At the end of the incubation period, Stop Solution was added to terminate the HRP-catalyzed reaction and stabilizes the color formed. The absorbance of each well at $450 \mathrm{~nm}$ was then measured using a microtiter plate reader $\left(\right.$ ChroMate $^{\mathrm{TM}} 4300$; Awareness Technology Inc., Palm City, FL, USA). IL-4 and IL-18 levels are expressed in picograms per milliliter.

\section{Statistical analysis}

Data analyses were performed using SPSS 16 (SPSS Inc., Chicago, IL, USA). The Wilcoxon signed-rank test was used to identify the statistical significance. Correlations were assessed with Spearman's correlation test, and P values $<0.05$ were considered significant.

\section{RESULTS}

There were no significant differences in serum IL-18 $(\mathrm{P}=0.261)$ and IL-4 $(\mathrm{P}=0.11)$ levels between the patient and controls groups. Table 2 shows IL-18 and IL-4 levels in the A-NHL patients and control subjects.

Table 2. Serum IL-18 and IL-4 values in non-Hodgkin's lymphoma patients and healthy controls.
\begin{tabular}{l|c|c|c|c|c}
\hline & \multicolumn{2}{|c|}{ Patients (N=46) } & \multicolumn{2}{c|}{ Controls $(\mathrm{N}=20)$} & P \\
\cline { 2 - 6 } & Median & Range & Median & Range & \\
\hline $\mathrm{IL}-18(\mathrm{pg} / \mathrm{mL})$ & 307.1 & $(29.6-1965.8)$ & 241.2 & $(104.5-1734.2)$ & 0.261 \\
\hline $\mathrm{IL}-4(\mathrm{pg} / \mathrm{mL})$ & 16 & $(9-27)$ & 14 & $(9-19)$ & 0.11 \\
\hline
\end{tabular}

None of the prognostic parameters analyzed significantly correlated with serum IL-4 concentration. This was also true for serum IL-18 values, with the exception of LDH. Serum IL-18 levels were elevated in patients with increased LDH compared to those with normal readings $(\mathrm{P}=0.045)$. In addition, we found no correlation between IL-18 and IL-4 measurements among A-NHL patients $(\mathrm{r}=0.188, \mathrm{P}=0.187)$. Table 3 shows the relationships between serum IL-18 and IL-4 levels and clinicopathological factors.

When we analyzed the effect of chemotherapy on serum parameters, we found that IL-4 levels had decreased following treatment, independently of response to from therapy $(\mathrm{P}=$ 0.002). However, serum IL-18 values were unchanged $(P=0.528$; Table 4).

Genetics and Molecular Research 15 (3): gmr.15038590 
Table 3. Relationships between serum interleukins and various demographic and disease characteristics.

\begin{tabular}{|c|c|c|c|}
\hline Parameter & Comparison & IL-18 & IL-4 \\
\hline Age & $(\leq 60$ vs $>60)$ & $\mathrm{ns}$ & $\mathrm{ns}$ \\
\hline Gender & (Male $v s$ female) & ns & ns \\
\hline Histology & (Diffuse large cell $v s$ others) & ns & ns \\
\hline Stage & $(\mathrm{I}, \mathrm{II} v s \mathrm{III}, \mathrm{IV})$ & ns & ns \\
\hline Performance status & $(0.1$ vs 2$)$ & ns & ns \\
\hline Response Rate & (Complete $v s$ partial) & ns & ns \\
\hline B-symptoms & (Absent $v s$ present) & ns & ns \\
\hline LDH & $(\leq 1 \mathrm{x}$ normal $v s>1 \mathrm{x}$ normal $)$ & 0.045 & ns \\
\hline Serum $\beta 2$ - microglobulin & $(\leq 1 \mathrm{x}$ normal $v s>1 \mathrm{x}$ normal $)$ & ns & ns \\
\hline Bone marrow involvement & (Positive $v s$ negative) & ns & ns \\
\hline Extra nodal lesion & (Yes $v s$ no) & ns & ns \\
\hline Progression & (Absent $v s$ present) & ns & ns \\
\hline
\end{tabular}

$\mathrm{LDH}=$ lactate dehydrogenase, $\mathrm{ns}=$ not significant.

Table 4. Distribution of serum IL-18 and IL-4 values in patients with non-Hodgkin's lymphoma before and after chemotherapy.

\begin{tabular}{l|c|c|c|c|c|}
\hline & \multicolumn{2}{|c|}{ Before chemotherapy } & \multicolumn{2}{c|}{ After chemotherapy } & P \\
\cline { 2 - 6 } & Median & Range & Median & Range & \\
\hline $\mathrm{IL}-18(\mathrm{pg} / \mathrm{mL})$ & 307.1 & $(29.6-1965.8)$ & 301.3 & $(72.8-1910.7)$ & 0.528 \\
\hline $\mathrm{IL}-4(\mathrm{pg} / \mathrm{mL})$ & 16 & $(9-27)$ & 14.3 & $(9.3-19.2)$ & 0.002 \\
\hline
\end{tabular}

\section{DISCUSSION}

The communication between malignant cells is considered as important as the genetic or epigenetic changes acquired by tumor cells. The bone marrow microenvironment contains hematolymphoid and stromal compartments, each, composed of a large number of cell types, including hematopoietic stem, blood, endothelial, and stromal cells. These secrete a wide array of soluble factors, orchestrating the survival and proliferation of transformed cells (Yu et al., 2016).

Modern techniques have demonstrated that cytokines exert broad and intriguing cellregulatory effects on a heterogeneous group of cell, forming a "cytokine network" (Fritsch et al., 1980). One current area of cytokine research concerns their role in the proliferation of neoplasms. Among human lymphoid malignancies, B-cell neoplasms have received the most attention in this respect (Cordingley et al., 1988; Biondi et al., 1989).

There exists strong evidence that tumor growth can be actively controlled by the host immune system and ILs are known to play a significant role in immune response regulation (Vendrame and Martínez-Maza, 2011). Previous studies have shown that; polymorphisms in a gene encoding an inflammatory mediator affect the biological activity of the corresponding protein, and may be associated with oncogenesis (Chen et al., 2015).

Recent reports have also revealed relationships between several ILs and nasopharyngeal, prostate, cervical, pancreatic, gastric, breast, and esophageal cancers, in addition to NHL (Guney et al., 2009; Chen et al., 2015; Li et al., 2015; Sun et al., 2015; Tas et al., 2015; Yu et al., 2015; Karabulut et al., 2016).

Inflammatory cytokines have an important influence on lymphoma pathogenesis and may reflect underlying biological processes, such as tumor-host interactions, providing prognostic information not afforded by conventional clinical parameters. Cytokines secreted

Genetics and Molecular Research 15 (3): gmr.15038590 
by tumor or host cells function as key mediators and/or regulators of tumor-host interactions causing the progression of malignancies (Turner et al., 2010).

IL-18 is a multifunctional cytokine of $18.3 \mathrm{kDa}$ synthesized by Kupffer cells, activated macrophages, keratinocytes, intestinal epithelial cells, osteoblasts, adrenal cortex cells, and the murine diencephalon (Gillespie and Horwood, 1998). In addition to multiple activities relating to its immunity-stimulating capacity, it exerts antitumor effects mediated by enhancement of NK cell activity, reduction of tumorigenesis, induction of apoptosis, and inhibition of angiogenesis in tumor cells. Recent data suggest that abnormal IL-18 production contributes to the pathogenesis of malignancies and may influence clinical outcome (Tas et al., 2015). Increased IL-18 levels have been detected in hematologic malignancies, for which this cytokine may serve as a sensitive serum marker of therapeutic effect and clinical course (Taniguchi et al., 1997; Takubo et al., 2000b).

IL-4 is produced by a sub-set of CD4+ T cells, basophiles and mast cells. It affects various steps in the human B-cell antigen-dependent maturation process and increases the expression of several functionally important surfaces antigens. IL-4 also regulates the differentiation of antigen-stimulated naïve T-cells which go on to produce IL-4 and a series of other cytokines including IL-10. Moreover, IL-4 is a key factor in tissue adhesion and the stimulation of B-cell growth (Nelms et al., 1999).

The aim of our study was to investigate serum IL-4 and IL-18 levels in A-NHL patients. The results were evaluated in relation to tumors prognostic parameters and chemotherapy.

No significant difference was established between the patient and control groups in terms of serum IL-4 and IL-18 levels. It is well known that serum IL-2, IL-6, and IL-10 concentrations are significantly higher in A-NHL patients than in healthy blood donors (Stasi et al., 1995; Fabre-Guillevin et al., 2006; Yu et al., 2015). Fabre-Guillevin et al. (2006) tested a large panel of cytokines using samples from A-NHL patients. They demonstrated that only IL-2 and IL-6 serum levels are elevated in high-grade NHL, while IL-4 concentration does not appear to be predictive of clinical development.

Contrary to our findings, Amo et al. (2001) found that serum IL-18 values are increased in cutaneous NK/T-cell lymphoma patients. Similarly, Taniguchi et al. (1997) reported that IL-18 levels in two groups of patients with acute lymphocytic and chronic myelocytic leukemia were significantly increased compared to the control group. In two studies carried out by Takubo et al. $(\mathrm{a}, \mathrm{c})$ IL-18 was also elevated in individuals with various hematologic disorders and 27 patients with NHL. The authors suggested that IL-18 may be produced in excess by lymphoma cells as a tumor- associated protein in hematological malignancies. Takada et al. (1999) found increased serum levels of this cytokine in patients with hemophagocytic lymphohistiocytosis, including those with anaplastic large-cell lymphoma or Epstein-Barr virus (EBV) infection. It has been suggested that tumor necrosis factor- $\alpha$ produced by T-cell lymphomas or EBV-infected T cells stimulates macrophages to produce IL-18 (Takada et al., 1999).

A second objective of our study was to investigate the relationship between serum prognostic factors and IL-4 and IL-18 levels. None of the prognostic parameters analyzed significantly correlated with serum IL-4 concentration. However, we determined a statistically significant relationship between IL-18 and LDH values.

The International Prognostic Index (IPI), taking into account A-NHL patient age, stage, LDH level, performance status, and number of extranodal sites, was devised by the International Non-Hodgkin's Lymphoma Prognostic Factor Project (1993). These criteria are used to determine aggressive lymphoma treatment plans and prognosies. There are several

Genetics and Molecular Research 15 (3): gmr.15038590 
examples in the literature, suggesting that high serum cytokine levels are important prognostic factors in A-NHL (Aydin et al., 2002; Guler et al., 2014; Uskudar Teke et al., 2014).

In an investigation by Fabre-Guillevin et al., (2006) serum IL-2, IL-4, IL-6, and IL-10 concentrations were compared against only two components of the IPI: B symptoms and Ann Arbor stage. In agreement with our results, no correlation established between IL-4 levels and prognostic factors. Further, we found a relationship between raised IL-18 and LDH measurements. To our knowledge, this is the first report to demonstrate such an association.

Also of note in the present study is the serum IL-4 level reduction that occurred because of chemotherapy, regardless of response to such treatment. We understand this to be the first study in which administration of chemotherapy triggered significant decrease in serum IL-4 levels.

This is the first report to measure the concentration of IL-18 and IL-4 by ELISA using serum samples from healthy individuals and A-NHL patients having received chemotherapy. However, two limitations to our study should be considered. First, owing to the rarity of A-NHL, the patient sample size in our study was relatively small and this may have limited our ability to identify statistically significant differences between group. Second, the development of A-NHL may be influenced by many other factors besides changes in IL activity.

In conclusion, it is not possible to determine the value of serum levels of these important cytokines in A-NHL patients based on this small study. The measurement of ILs in serum samples may be a cost effective, convenient and minimally invasive method of utilizing these easily accessible potential biomarkers of treatment response and outcome. Larger-scale research is needed in this field, and exciting new finding will ultimately ensue. In addition, considering the critical role that they play in the differentiation and proliferation of normal and neoplastic B-cells, further investigation of the biological impact of high levels of cytokines on lymphoma pathogenesis and progression is warranted.

\section{Conflicts of interest}

The authors declare no conflict of interest.

\section{ACKNOWLEDGMENTS}

Research supported by the Istanbul University Research Fund (\#1825).

\section{REFERENCES}

Alici S, Bavbek SE, Kaytan E, Eralp Y, et al. (2003). Prognostic factors in localized aggressive non-Hodgkin' s lymphoma. Am. J. Clin. Oncol. 26: 1-5. http://dx.doi.org/10.1097/00000421-200302000-00001

Amo Y, Ohta Y, Hamada Y and Katsuoka K (2001). Serum levels of interleukin-18 are increased in patients with cutaneous T-cell lymphoma and cutaneous natural killer-cell lymphoma. Br. J. Dermatol. 145: 674-676. http:// dx.doi.org/10.1046/j.1365-2133.2001.04420.x

Aydin F, Yilmaz M, Ozdemir F, Kavgaci H, et al. (2002). Correlation of serum IL-2, IL-6 and IL-10 levels with International Prognostic Index in patients with aggressive non-Hodgkin's lymphoma. Am. J. Clin. Oncol. 25: 570572. http://dx.doi.org/10.1097/00000421-200212000-00007

Biondi A, Rossi V, Bassan R, Barbui T, et al. (1989). Constitutive expression of the interleukin-6 gene in chronic lymphocytic leukemia. Blood 73: 1279-1284.

Chen CH, Gong M, Yi QT and Guo JH. (2015). Role of interleukin-6 gene polymorphisms in the development of prostate cancer. Genet. Mol. Res. 14: 13370-13374. http://dx.doi.org/10.4238/2015.October.26.34

Cordingley FT, Bianchi A, Hoffbrand AV, Reittie JE, et al. (1988). Tumour necrosis factor as an autocrine tumour growth factor for chronic B-cell malignancies. Lancet 1: 969-971.http://dx.doi.org/10.1016/S0140-6736(88)91782-5

Genetics and Molecular Research 15 (3): gmr.15038590 
Fabre-Guillevin E, Tabrizi R, Coulon V, Monnereau A, et al. (2006). Aggressive non-Hodgkin'-s lymphoma: concomitant evaluation of interleukin-2, soluble interleukin-2 receptor, interleukin-4, interleukin-6, interleukin-10 and correlation with outcome. Leuk. Lymphoma 47: 603-611. http://dx.doi.org/10.1080/10428190500361029

Fritsch EF, Lawn RM and Maniatis T (1980). Molecular cloning and characterization of the human beta-like globin gene cluster. Cell 19: 959-972. http://dx.doi.org/10.1016/0092-8674(80)90087-2

Gillespie MT and Horwood NJ. (1998). Interleukin-18: perspectives on the newest interleukin. Cytokine Growth Factor Rev. 9: 109-116. http://dx.doi.org/10.1016/S1359-6101(98)00004-5

Guler N, Kelkitli E, Atay H, Erdem D, et al. (2014). The relationship of T helper-2 pathway components interleukin-4, interleukin-10, immunoglobulin E, and eosinophils with prognostic markers in non-Hodgkin lymphoma: a casecontrol study. Turk. J. Haematol. 31: 381-387. http://dx.doi.org/10.4274/tjh.2013.0328

Guney N, Soydinc HO, Basaran M, Bavbek S, et al. (2009). Serum levels of interleukin-6 and interleukin-10 in Turkish patients with aggressive non-Hodgkin's lymphoma. Asian Pac. J. Cancer. Prev. 10: 669-674.

Karabulut S, Afsar ÇU, Karabulut M, Alış H, et al. (2016). Evaluation of serum Interleukin-17 (IL-17) levels as a diagnostic marker in pancreatic adenocarcinoma. J. Gastrointest. Cancer. 47: 47-54. http://dx.doi.org/10.1007/ $\underline{\text { s12029-015-9787-z }}$

Kawakami Y, Rosenberg SA, and Lotze MT. (1988). Interleukin 4 promotes the growth of tumor-infiltrating lymphocytes cytotoxic for human autologous melanoma. J. Exp. Med. 168: 2183-2191.http://dx.doi.org/10.1084/jem.168.6.2183

Li X, Ren D, Li Y, Xu J, et al. (2015). Increased cancer risk associated with the -607C/A polymorphism in interleukin-18 gene promoter: an updated meta-analysis including 12,502 subjects. J. BUON. 20: 902-917.

Miles RR, Shah RK and Frazer JK (2016). Molecular genetics of childhood, adolescent and young adult non-Hodgkin lymphoma. Br. J. Haematol. DOI: http://dx.doi.org/10.1111/bjh.14011. (in press).

Miller TP, Lippman SM, Spier CM, Slymen DJ, et al. (1988). HLA-DR (Ia) immune phenotype predicts outcome for patients with diffuse large cell lymphoma. J. Clin. Invest. 82: 370-372. http://dx.doi.org/10.1172/JCI113598

Nelms K, Keegan AD, Zamorano J, Ryan JJ, et al. (1999). The IL-4 receptor: signaling mechanisms and biologic functions. Annu. Rev. Immunol. 17: 701-738. http://dx.doi.org/10.1146/annurev.immunol.17.1.701

Parkinson DR, Sznol M and Cheson BD (1993). Biologic therapies for low-grade lymphomas. Semin. Oncol. 20 (Suppl 5): 111-117.

Paul WE (1991). Interleukin-4: a prototypic immunoregulatory lymphokine. Blood 77: 1859-1870.

Purdue MP, Lan Q, Bagni R, Hocking WG, et al. (2011). Prediagnostic serum levels of cytokines and other immune markers and risk of non-hodgkin lymphoma. Cancer Res. 71: 4898-4907. http://dx.doi.org/10.1158/0008-5472. CAN-11-0165

Saito H, Hatake K, Dvorak AM, Leiferman KM, et al. (1988). Selective differentiation and proliferation of hematopoietic cells induced by recombinant human interleukins. Proc. Natl. Acad. Sci. U S A. 85: 2288-2292. http://dx.doi. org/10.1073/pnas.85.7.2288

Spits H, Yssel H, Takebe Y, Arai N, et al. (1987). Recombinant interleukin 4 promotes the growth of human T cells. $J$. Immunol. 139: 1142-1147.

Stasi R, Zinzani L, Galieni P, Lauta VM, et al. (1995). Clinical implications of cytokine and soluble receptor measurements in patients with newly-diagnosed aggressive non-Hodgkin's lymphoma. Eur. J. Haematol. 54: 9-17. http://dx.doi. org/10.1111/j.1600-0609.1995.tb01619.x

Sun LX, Wang XB, and Huang XJ (2015). Association analysis of rs2275913G $>$ A and rs763780T $>C$ interleukin 17 polymorphisms in Chinese women with cervical cancer. Genet. Mol. Res. 14: 13612-13617.

Takada H, Ohga S, Mizuno Y, Suminoe A, et al. (1999). Oversecretion of IL-18 in haemophagocytic lymphohistiocytosis: a novel marker of disease activity. Br. J. Haematol. 106: 182-189. http://dx.doi.org/10.1046/j.1365-2141.1999.01504.x

Takubo T, Kumura T, Nakao T, Nakamae H, et al. (2000a). Comparative study on complete remission rate and overall survival in three groups classified based on the serum interleukin-18 level in non-Hodgkin's lymphoma patients. Acta. Haematol. 104: 220-222. http://dx.doi.org/10.1159/000046520

Takubo T, Kumura T, Nishiki S, Kinoshita Y, et al. (2000b). Clinical significance of simultaneous determination of serum soluble transferrin receptor, soluble Fas, soluble Fas ligand, hepatocyte growth factor and interleukin 18 levels in a patient with hemophagocytic syndrome. Acta. Haematol. 103: 165-167. http://dx.doi.org/10.1159/000041041

Takubo T, Ohkura H, Kumura T, Ohta K, et al. (2000c). Serum IL-18 levels in patients with various hematological disorders. Haematologia (Budap). 30: 31-33. http://dx.doi.org/10.1163/15685590051129850

Taniguchi M, Nagaoka K, Kunikata T, Kayano T, et al. (1997). Characterization of anti-human interleukin-18 (IL-18)/ interferon-gamma-inducing factor (IGIF) monoclonal antibodies and their application in the measurement of human IL-18 by ELISA. J. Immunol. Methods 206: 107-113. http://dx.doi.org/10.1016/S0022-1759(97)00094-X

Tas F, Tilgen Yasasever C, Karabulut S, Tastekin D, et al. (2015). Clinical significance of serum interleukin-18 (IL-18) levels in patients with gastric cancer. Biomed. Pharmacother. 70: 19-23.http://dx.doi.org/10.1016/j.biopha.2014.12.040

Genetics and Molecular Research 15 (3): gmr.15038590 
International Non-Hodgkin's Lymphoma Prognostic Factor Project (1993). A predictive model for aggressive nonHodgkin's Lymphoma. N. Engl. Med. 329: 987-994.http://dx.doi.org/10.1056/NEJM199309303291402

Treisman J, Higuchi CM, Thompson JA, Gillis S, et al. (1990). Enhancement by interleukin 4 of interleukin 2- or antibodyinduced proliferation of lymphocytes from interleukin 2-treated cancer patients. Cancer Res. 50: 1160-1164.

Turner JJ, Morton LM, Linet MS, Clarke CA, et al. (2010). InterLymph hierarchical classification of lymphoid neoplasms for epidemiologic research based on the WHO classification (2008): update and future directions. Blood 116: e90-e98.http://dx.doi.org/10.1182/blood-2010-06-289561

Ushio S, Namba M, Okura T, Hattori K, et al. (1996). Cloning of the cDNA for human IFN-gamma-inducing factor, expression in Escherichia coli, and studies on the biologic activities of the protein. J. Immunol. 156: 4274-4279.

Uskudar Teke H, Gulbas Z, and Bal C (2014). Serum levels of cytokines and prevalence of autoantibodies in lymphoma patients and their prognostic value. J. BUON. 19: 191-197.

Vendrame E and Martínez-Maza O (2011). Assessment of pre-diagnosis biomarkers of immune activation and inflammation: insights on the etiology of lymphoma. J. Proteome. Res. 10: 113-119.http://dx.doi.org/10.1021/pr100729z

Yu YF, Han ZG, Guo WB, Zhang GJ, et al. (2015). Interleukin-10 polymorphisms and nasopharyngeal carcinoma risk: a meta-analysis. Genet. Mol. Res. 14: 18945-57. http://dx.doi.org/10.4238/2015.December.29.1

Yu L, Zhao Y, Gu X, Wang J, et al. (2016). Dual effect of LPS on murine myeloid leukemia cells: pro-proliferation and anti-proliferation. Exp. Cell. Res. DOI: http://dx.doi.org/10.1016/j.yexcr.2016.03.006. (in press).

Zhang Y, Xia ZG, Zhu JH, Chen MB, et al. (2015). Association of Interleukin-10 -3575T $>$ A and -1082A > G polymorphisms with non-Hodgkin lymphoma susceptibility: a comprehensive review and meta-analysis. Mol. Genet. Genomics. 299: 2063-2073. http://dx.doi.org/10.1007/s00438-015-1058-y

Genetics and Molecular Research 15 (3): gmr.15038590 